\title{
A diagnostic survey of infants referred for chromosome analysis in the neonatal period
}

\author{
R M WINTER, M A C RIDLER, J A MCKEOWN
}

\begin{abstract}
Summary and conclusions
Examination and assessment of 140 liveborn and stillborn infants referred within two weeks of birth for chromosome analysis showed that 48 had Down's syndrome, 12 other chromosome abnormalities, 17 single gene disorders, 18 recognisable anomalads, 8 recognisable syndromes of unknown aetiology, and the remainder were undiagnosed. Of the non-Down's cases that were diagnosed, $21 \%$ had a chromosomal abnormality. These results suggest that a request for chromosome analysis in the newborn period should be viewed as one step in syndrome identification.
\end{abstract}

\section{Introduction}

The indications for chromosome analysis within the newborn period are well established. A suspected chromosomal syndrome, usually trisomy 21 , is the most common reason for a request for chromosome studies. Other indications include multiple congenital malformations, ambiguous genitalia, or "an odd-looking baby."

The Kennedy-Galton Centre for clinical genetics provides a comprehensive clinical genetics service, including facilities for

Kennedy-Galton Centre for Clinical Genetics, Harperbury Hospital, Radlett, Herts WD7 9HQ

R M WINTER, BSC, MRCP, senior registrar in clinical genetics (and at Division of Inherited Metabolic Diseases, Clinical Research Centre, Northwick Park Hospital, Harrow, Middlesex HA1 3UJ)

M A C RIDLER, PHD, principal scientific officer

J A MCKEOWN, Bsc, senior scientific officer chromosome analysis, syndrome identification, and genetic counselling. Since the establishment of the centre by Professor Lionel S Penrose, the policy has been to offer a service to local paediatricians, obstetricians, and pathologists who request chromosome analysis on a newborn or stillborn infant. A member of the clinical or scientific staff visits the referring hospital, examines the infant, takes blood or skin samples for chromosome analysis, suggests further investigations, and makes a photographic record of any abnormal physical features. No attempt is made to counsel the parents at this stage and, so far as is possible, the geneticist does not communicate any diagnostic suspicions directly without first consulting the local clinician. In this way the risk of parents obtaining conflicting opinions is minimised at a time when they are struggling to come to terms with the birth of an abnormal baby.

The present survey analyses the outcome of 140 such visits in order to assess the contribution of chromosome analysis and an early opinion by a geneticist to the diagnosis of the malformed infant.

\section{Materials and methods}

All the cases were referred by a clinician or pathologist within two weeks of birth specifically for chromosome analysis, and were assessed by a member of the Kennedy-Galton staff within that period. Both stillbirths and liveborn infants were included in the series. We report 140 consecutive cases seen over a three-year period (1977-9). Most karyotypes were analysed from lymphocyte cultures. G-banding was routinely carried out, and other staining methods were used where indicated. Occasionally, fibroblast cultures were established and analysed to exclude mosaicism or, in the case of stillborn infants, where viable blood samples were not available. During the three-year period a total of 992 lymphocyte cultures were carried out for diagnostic purposes at the Kennedy-Galton Centre; therefore the present sample represents a subset of around $14 \%$. 
When a specific diagnosis was suggested by the clinician as a reason for referral this was recorded. Only diagnoses made from clinical and pathological material obtained in the newborn period are included in the analysis. Infants undiagnosed in the newborn period-but subsequently given a diagnosis on reassessment at a later age-are labelled as undiagnosed.

Cases were classified into groups according to reason for referral. One of five reasons for referral was usually given: (i) suspected Down's syndrome; (ii) suspected chromosome abnormality specified by name (other than Down's syndrome); (iii) specified malformations; (iv) ambiguous genitalia ; or (v) odd-looking baby-that is, dysmorphic facial features with no other malformations.

The final "diagnoses" are classified after Smith. ${ }^{1}$

Known aetiology-(i) Down's syndrome (including translocation cases); (ii) other chromosomal abnormalities; or (iii) single gene abnormalities.

Unknown aetiology-(i) Anomalads (defined as a malformation together with its subsequently derived structural changes-for instance, Robin anomalad); (ii) recognised syndromes and associations of unknown aetiology; or (iii) sporadic, ideopathic malformations (not recognised to be a specific syndrome).

No diagnosis (including ambiguous genitalia).

\section{Results}

The table summarises the results. The reasons for referral are given in the left-hand column, and the numbers and percentages of the final diagnoses within each referral group are obtained by reading along the rows. The penultimate row represents the numbers and percentages within each diagnostic category, and the last row represents the percentage contribution of non-Down's syndrome cases to the remaining diagnostic categories. Detailed diagnoses are given in the appendix. In a few cases an infant is classified according to the most likely diagnosis suggested by the physical features at birth, although, because of the nature of the condition, follow-up at a later age would be necessary for absolute confirmation. These infants are marked by a "?."

\section{Discussion}

As would be expected a large proportion, about one-third of all cases referred, had Down's syndrome. Of these, two out of 48 were due to translocations, the rest being standard trisomy 21 . All cases finally diagnosed as having Down's syndrome were referred with this diagnosis. Of those referred because of suspected Down's syndrome, only one infant-a Chinese baby with the Hallermann-Streiff syndrome-was given a definitive diagnosis other than Down's syndrome, and in $15 \%$ the initial suspicion of Down's syndrome was not confirmed.

The other autosomal and sex chromosomal aneuploidies were usually referred with the specific diagnosis already suggested; however, some cases with rarer manifestations, such as radial aplasia in trisomy 18 , were not diagnosed clinically.

In virtually three-quarters of cases referred because of malformations a definitive diagnosis could be given. Almost a third of cases had well-recognised anomalads (see appendix). In some of these cases chromosome analysis is more worth while than in others. For example, it is well recognised that holoprosencephaly can be part of chromosome syndromes (trisomy
13, 4p-, 13q-, 18p-, triploidy, etc). ${ }^{2}$ In other cases, such as neural tube defects or exstrophy of the bladder, a chromosomal defect is not usually found. ${ }^{3}$ Nevertheless, the present series, did provide some chance associations-for example, one case of Down's syndrome with bilateral renal agenesis. In about twofifths of cases referred because of malformation a recognisable syndrome or association could be diagnosed (either due to a single gene or of unknown aetiology). Chromosomal abnormalities accounted for about $5 \%$ of the malformation referral group.

The four infants referred because of ambiguous genitalia were not given a more specific clinical diagnosis within the first two weeks of life; they are, therefore, placed in a separate diagnostic category.

Finally, of the 15 infants referred because of isolated oddlooking faces, three $(20 \%)$ had chromosome abnormalities, the remainder being undiagnosed.

Overall, of the non-Down's syndrome cases, $60 \%$ were given a definitive diagnosis, the remainder being classified under ideopathic malformations (15\%), ambiguous genitalia (4.5\%), or undiagnosed odd-looking babies $(21 \%)$. A follow-up study of the last group to monitor development would be valuable. Thirteen per cent of non-Down's syndrome cases had chromosomal abnormalities. This figure may be compared with the roughly $0.5 \%$ incidence of chromosomal aneuploidy found in surveys of newborn infants unselected for abnormal clinical features. ${ }^{4}$ The relatively low percentage contribution of chromosomal diagnoses to the total number of diagnosed cases would suggest that the request for chromosome analysis in the neonatal period should be seen as one step in a general process of "syndrome identification," so that a normal karyotype should stimulate the clinician into further efforts to establish a diagnosis. The inclusion of a geneticist early on in this process of diagnosis not only ensures the efficient collection and transport of specimens for chromsome analysis but also provides an extra opinion from someone who deals regularly with such problems. The benefits of an early diagnosis to the management of the abnormal neonate and his or her family should be self-evident.

We thank all the paediatricians, obstetricians, and pathologists for allowing us to visit their patients. All cases were discussed with $\mathrm{Dr} M$ Baraitser and Dr M d'A Crawfurd, to whom many thanks are due for helpful suggestions leading to many of the diagnoses.

\section{Appendix}

CLASSIFICATION OF PATIENTS ACCORDING TO FINAL DIAGNOSIS

Known aetiology

No Diagnosis

Reason for referral

$\begin{array}{rl}30 & 47, X Y,+21 \\ 16 & 47, X X,+21 \\ 1 & 46, X Y, t(14 q, 21 q) \\ 1 & 46, X Y, t(21 \mathrm{q}, 21 \mathrm{q})\end{array}$

Results of examination of 140 stillborn and liveborn infants within two weeks of birth for chromosome analysis

\begin{tabular}{|c|c|c|c|c|c|c|c|c|c|c|c|c|c|c|}
\hline & & & & & & $\begin{array}{c}\text { "Diagnosis" } \\
\text { Down's } \\
\text { syndrome }\end{array}$ & $\begin{array}{l}\text { Other } \\
\text { chromosomal } \\
\text { abnormality }\end{array}$ & $\begin{array}{l}\text { Single } \\
\text { gene } \\
\text { disorder }\end{array}$ & Anomalad & $\begin{array}{c}\text { Known } \\
\text { syndromes or } \\
\text { associations }\end{array}$ & $\begin{array}{l}\text { Sporadic, } \\
\text { ideopathic } \\
\text { malformations }\end{array}$ & $\begin{array}{c}\text { Ambiguous } \\
\text { genitalia }\end{array}$ & $\begin{array}{l}\text { "No } \\
\text { diagnosis" }\end{array}$ & $\begin{array}{l}\text { Total } \\
(\%)\end{array}$ \\
\hline \multicolumn{5}{|c|}{ 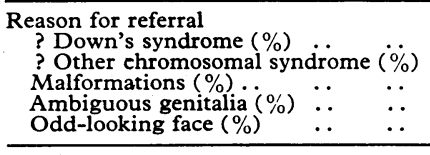 } & $\begin{array}{l}\ldots \\
\because \\
\cdots\end{array}$ & $48(85 \cdot 5)$ & $\begin{array}{l}6(60) \\
3(5 \cdot 5) \\
3(20)\end{array}$ & $\begin{array}{r}1(10) \\
16(29)\end{array}$ & $\begin{array}{r}1(10) \\
17(31)\end{array}$ & $\begin{array}{l}1(2) \\
5(9) \\
2(13.5)\end{array}$ & $14(25 \cdot 5)$ & $4(100)$ & $\begin{array}{l}7(12.5) \\
2(20) \\
10(66.5)\end{array}$ & $\begin{array}{l}56(40) \\
10(7) \\
55(39 \cdot 5) \\
4(3) \\
15(10 \cdot 5)\end{array}$ \\
\hline Totals (\%) & .. & $\ldots$ & $\ldots$ & $\ldots$ & . & $48(34 \cdot 5)$ & $12(8 \cdot 5)$ & $17(12)$ & $18(13)$ & $8(5 \cdot 5)$ & $14(10)$ & $4(3)$ & $19(13.5)$ & $140(100)$ \\
\hline \multicolumn{5}{|c|}{ Non-Down's syndrome cases (\%) } & $\ldots$ & & (13) & $(18 \cdot 5)$ & $(19 \cdot 5)$ & $(8 \cdot 5)$ & (15) & $(4 \cdot 5)$ & $(21)$ & $(100)$ \\
\hline
\end{tabular}


Other chromosomal abnormalities

$47, \mathrm{XY},+13$
$47, \mathrm{XX},+18$
$47, \mathrm{XY},+18$
$45, \mathrm{XO}$
$46, \mathrm{XX}, \operatorname{dup}(6)(\mathrm{p} 21 \mathrm{p} 25)$
$46, \mathrm{XX}, \operatorname{del}(13)(\mathrm{pter} \rightarrow \mathrm{q} 21:: \mathrm{q} 32 \rightarrow \mathrm{qter})$
$69, \mathrm{XXY}$
$47, \mathrm{XY},+18$
$46, \mathrm{XX}, \operatorname{del}(5)(\mathrm{p} 14)$
$46, \mathrm{XY}, \operatorname{del}(7)(\mathrm{pter} \rightarrow \mathrm{p} 21:: \mathrm{p} 13 \rightarrow \mathrm{qter})$
$47, \mathrm{XY},+18 \mathrm{q}-$

? Trisomy 13

Trisomy 18

Trisomy 18

? Turner's syndrome

Turner's syndrome

? Turner's syndrome

Malformation

Malformation

Odd-looking face

dd-looking face

Odd-looking face

\section{Single gene disorders}

Pseudotrisomy 18

Asphyxiating, thoracic dystrophy

B.B.B. (Opitz,

hypertelorism-hypospadias)

syndrome

Pfeiffer syndrome

Pena Shokeir syndrome

Smith-Lemli-Opitz syndrome

Autosomal recessive microcephaly

Langer-Giedion syndrome ?

Syndactyly type 1

Neu-Laxova syndrome

Marden-Walker syndrome ?

$\mathrm{HARD} \pm \mathrm{E}$ syndrome

Preaxial polydactyly type IV

Schinzel-Giedion syndrome

Pseudotrisomy 18

"Private syndrome"*

\section{? Trisomy $18^{5}$}

Malformation ${ }^{1}$

Malformation ${ }^{1}$

Malformation ${ }^{1}$

Malformation ${ }^{6}$

Malformation ${ }^{1}$

Malformation ${ }^{5}$

Malformation ${ }^{1}$

Malformation ${ }^{\text {? }}$

Malformation $^{8}$

Malformation $^{9}$

Malformation ${ }^{10}$

Malformation ${ }^{7}$

Malformation ${ }^{11}$

Malformation ${ }^{5}$

Leucodystrophy,

hepatosplenomegaly

(*Female infant with previously undescribed neurodegenerative disease. History of male sibling who died with the same disorder.)

\section{Unknown aetiology}

\section{Miscellaneous anomolads}

1 Renal agenesis

3 Premaxillary agenesis/

holoprosencephaly

Encephalocele

3 Neural tube defects

Hydranencephaly

Di George syndrome

Extrophy of bladder

Prune belly syndrome

Renal agenesis

Cleft lip/palate

Pierre-Robin anomalad

Hypoplastic left heart

Exomphalos

\section{? Trisomy 18}

Malformation

Malformation

Malformation

Malformation

Malformation

Malformation

Malformation

Malformation

Malformation

Malformation

Malformation

Malformation

\section{Syndromes of unknown aetiology}

1 Hallermann-Strieff syndrome de Lange syndrome

1 Unusual facies/femoral hypoplasia syndrome

Vater association

Thanatophoric dysplasia

Pseudosirenomelia

de Lange syndrome
? Down's syndrome ${ }^{1}$

Malformation ${ }^{1}$

Malformation ${ }^{1}$

Malformation ${ }^{1}$

Malformation ${ }^{1}$

Malformation ${ }^{12}$

Odd-looking face ${ }^{1}$

\section{Multiple, ideopathic malformations}

Encephalocele, 1st and 2nd branchial arch anomaly, radial defects. Microphthalmos and corneal clouding, (R) eye.

Cleft palate, microphthalmia, congenital heart disease, distal limb defects, unilateral multicystic kidney.

Microcephaly, high arched palate.

Microcephaly, cataracts.

Potter's facies, genital anomalies.

Micrognathia, cleft palate, microcephaly, flexion deformity of hands, clitoral hypertrophy.
External ear anomalies, congenital heart defect.

Phocomelia, exomphalos.

Hydrops foetalis.

Arthrogryposis, pedunculated toes.

Lop ears, ear fistulas.

Hydrocephalus, hypospadias.

Microcephaly, dysmorphic facial features.

\section{No diagnosis}

\section{No Reason for referral \\ 2 Ambiguous genitalia $(46, \mathrm{XY})$ \\ 2 Ambiguous genitalia (46,XX) \\ 7 ? Down's syndrome \\ 2 ? Turner's syndrome \\ 10 Odd-looking face}

\section{References}

1 Smith DW. Recognisable patterns of human malformation. 2nd ed. Philadelphia: W B Saunders Company, 1976.

2 Gorlin RJ, Pindborg JJ, Cohen MM. Syndromes of the head and neck. 2nd ed. New York: McGraw-Hill, 1976:356.

3 Sutherland GR, Carter RF, Bauld R, Smith II, Bain AD. Chromosome studies at the paediatric necropsy. Ann Hum Genet 1978;42:173-81.

4 Buckton KE, O'Riordan ML, Ratcliffe S, et al. A G-band study of chromosomes in liveborn infants. Ann Hum Genet 1980;43:227-39.

s Holmes LB, Moser HW, Halldorsson S, Mack C, Pant SS, Matzilevich B. Mental retardation; an atlas of diseases with associated physical abnormalities. New York: Macmillan, 1972:336.

- Pena SDJ, Shokeir MHK. Syndrome of camptodactyly, multiple ankyloses, facial anomalies, and pulmonary hypoplasia. Further delineation and evidence for autosomal recessive inheritance. Birth Defects 1976;xii, No $5: 201-8$.

7 Temtamy SA, McKusick VA. The genetics of hand malformations. Birth Defects 1978;xiv, No 3:382.

${ }^{8}$ Neu RL, Kajii T, Gardner LJ, Nagyfy SF, King S. A lethal syndrome of microcephaly with multiple congenital anomalies in three siblings. Pediatrics $1971 ; 47: 610-2$.

9 Bergsma D, ed. Birth defects compendium. 2nd ed. London: Macmillan, 1979:680.

10 Pagon RA, Chandler JW, Collier WR, et al. Hydrocephalus, agyria, retinal dysplasia, encephalocoele $(\mathrm{HARD} \pm \mathrm{E}$ ) syndrome: an autosomal recessive condition. Birth Defects 1978 ;xiv, No 6B:233-41.

11 Schinzel A, Giedion A. A syndrome of severe midface retraction, multiple skull anomalies, clubfeet, and cardiac and renal malformations in sibs. Am $\mathcal{7}$ Med Genet 1978;1:361-75.

12 Le Marec B, Kerisit J, Maffeis, JL, De Champchesnel T, Duval JM. True sirenomelia and pseudo-sirenomelia. International Conference on Birth Defects, Vienna, 1973. Amsterdam: Excerpta Medica, 1973:34.

(Accepted 8 August 1980)

Are special (and expensive) wetting solutions necessary for the insertion of hard contact lenses or would sterile water suffice?

A wetting solution coats a hard lens with a chemical that permits water to spread and form a surface that is less traumatic to eye tissues. Tears contain nature's own wetting agent in the form of tear proteins, which eventually replace the artificial wetting solutions. Sterile water would not necessarily wet the surface of the contact lens and would also be expensive. Sterile water, presumably without preservatives, would have to be supplied in unit-dose containers to comply with licensing regulations or alternatively in pressurised can containers. The conventional hard PMMA lens is often washed and cleaned in a nonirritant detergent and then rinsed with tap water before insertion, the patients' hands having first been washed and dried. But for convenience solutions for wetting, storage, rinsing, lubrication, etc, have been prepared by manufacturers. There are several new gas-permeable and specially coated hard lenses that according to the manufacturer require only their special wetting agents. Therefore in all instances it is best to consult the practitioner (and he in turn the manufacturer) about the regimen to be followed. Since wetting solutions (and indeed all preparations used with contact lenses) are now subject to licensing regulations, as will contact lenses be at some future date, it is no longer safe to generalise, but the practitioner should seek advice when in doubt from the data sheets and information issued by the manufacturer of the solutions and contact lenses. 